\title{
Circulating Tumor Cells Accurately Predicting Progressive Disease After Treatment in a Patient with Non-small Cell Lung Cancer Showing Response on Scans
}

\author{
CRISTA E. HORTON ${ }^{1}$, MOHAMED KAMAL ${ }^{2}$, MACALL LESLIE $^{2}$, ROY ZHANG $^{3}$, \\ TAKEMI TANAKA $^{2,3^{*}}$ and MOHAMMAD RAZAQ ${ }^{4 *}$ \\ ${ }^{1}$ College of Medicine, University of Oklahoma Health Sciences Center, Oklahoma City, OK, U.S.A.; \\ ${ }^{2}$ Stephenson Cancer Center, University of Oklahoma Health Sciences Center, Oklahoma City, OK, U.S.A.; \\ ${ }^{3}$ Department of Pathology, College of Medicine, \\ University of Oklahoma Health Sciences Center, Oklahoma City, OK, U.S.A.; \\ ${ }^{4}$ Division of Hematology and Oncology, College of Medicine, Stephenson Cancer Center, \\ University of Oklahoma Health Sciences Center, Oklahoma City, OK, U.S.A.
}

\begin{abstract}
Lung cancer is the leading cause of cancerrelated deaths worldwide. Most patients present with advanced inoperable disease. Traditionally, responses to treatments are evaluated using different imaging modalities, which can sometimes be confusing. This is particularly more relevant in stage 3 disease where, after radiation therapy, persistent tumors on scans can represent active disease or scar tissue. We have been evaluating role of circulating tumor cells (CTCs) in that setting. Here we present the case of a 68-year-old male with stage 3 disease whose primary tumor responded to chemoradiotherapy on imaging, but whose CTC count was higher than the pre-treatment value. The patient later developed liver metastases. In this case, the CTC count more accurately predicted the patient's prognosis and highlights the need for exploration of the CTC count as a tool supplemental to imaging modalities.
\end{abstract}

Lung cancer is the leading cause of cancer-related deaths worldwide, with the majority of patients presenting with

Correspondence to: Mohammad Razaq, MD, Assistant Professor of Medicine, University of Oklahoma Health Sciences Center, College of Medicine, Division of Hematology and Oncology, Stephenson Cancer Center, 800 NE 10th Street, Oklahoma City, OK 73013, U.S.A. Tel: +1 4052714022 (Office), e-mail: Mohammadrazaq@ouhsc.edu and Takemi Tanaka, Ph.D. Associate Professor, Stephenson Cancer Center, OU School of Medicine, Department of Pathology University of Oklahoma Health Science Center 975 NE, 10th, BRC-W, Rm1415, Oklahoma City, OK, 73104, U.S.A. Tel: +1 4052718260, e-mail: takemi-tanaka@ouhsc.edu

Key Words: Non-small cell lung cancer, circulating tumor cells, tumor response. inoperable, metastatic disease (1). Currently, lung cancer response to treatment is assessed using conventional imaging and Response Evaluation Criteria in Solid Tumors (RECIST) (2). Circulating tumor cells (CTCs) have received much interest as an excellent biomarker, enabling liquid biopsies, and longitudinal and non-invasive disease monitoring that captures an overall snapshot of individual disease (3). Studies support a parallel association between the number of CTCs, therapeutic response, RECIST response, and prognosis (4-7).

In the case we report here, the change in CTC number post therapy was discordant with the RECIST response. While the primary non-small cell lung cancer (NSCLC) tumor appeared to respond to chemoradiation, the number of CTCs continued to rise; imaging was not able to detect micrometastases and eventual disease recurrence. The CTC count, while discordant with imaging, accurately predicted the patient's prognosis. This case highlights the need for the exploration of CTCs as a tool supplemental to imaging modalities.

\section{Case Report}

A 68-year-old male former smoker presented to the Emergency Department with acute chest pain. Chest computed tomography (CT) found a $5.5 \times 4.4 \mathrm{~cm}$ lobulated soft-tissue mass in the right hilum, with proximity to the pulmonary artery. Positron-emission tomography (PET) revealed the mass to be hypermetabolic, with a maximum standardized uptake value of 16.7. Bronchoscopic biopsy confirmed a diagnosis of poorly differentiated squamous cell carcinoma (T4N0M0, IIIA). The patient was deemed not to be a candidate for surgery. 
Pre-treatment chest CT revealed mass growth to $6.1 \times 4.8$ $\mathrm{cm}$ extending into the right middle lobe with encasement of the right interlobar artery. The CTC count from $10 \mathrm{ml}$ of blood from the same day was determined to be 2 (Figure 1). One week later, the patient started standard radiation and chemotherapy with seven cycles of weekly carboplatin and paclitaxel. Post-treatment CT showed partial response with $44.26 \%$ reduction in tumor size, at which time the CTC count had increased to 10 (Figure 1). At that time, the patient received two more cycles of consolidation chemotherapy with higher dosages of carboplatin and paclitaxel.

Three months later, abdominal PET/CT demonstrated a new $1.5 \mathrm{~cm}$ hypoenhancing lesion in the right hepatic lobe consistent with metastasis (Figure 2). CT-guided biopsy showed a poorly differentiated squamous cell carcinoma with histology consistent with liver metastasis.

\section{Discussion}

Despite shrinkage of primary tumor, this patient's CTC count drastically increased post-treatment. He later developed disease metastatic to the liver. We believe this patient had radiosensitive disease, resulting in the shrinkage of tumor in the radiation field, but his disease was resistant to chemotherapy. This resulted in an increase in CTCs. Studies have reported 70-90\% concordance between imaging and CTCs $(4,8)$. In fact, Budd et al. were able to separate breast cancer with progressive disease on images in two prognostic groups based on CTCs (8).

As the majority of patients with higher-stage NSCLC show progression of disease, this case highlights the notion that CTCs might predict resistance to treatment and persistence of disease even when imaging shows a response to therapy. Employing secondary methods, such as the CTC count to sensitively predict metastasis could potentially offset limitations of imaging. CTCs also have potential utility in rapid evaluation of chemotherapy effect in advance lung cancer and monitoring of lung cancer recurrence in early stage lung cancer (9). There are various CTC techniques that are under investigations and there is significant variability among these techniques. These techniques need to be standardized and larger prospective trials are needed to evaluate their utility in clinical settings. This case highlights the need for such studies and the possibility of those studies having far reaching implications.

\section{References}

1 Howlader N, Noone AM, Krapcho M, Miller D, Bishop K, Kosary CL, Yu M, Ruhl J, Tatalovich Z, Mariotto A, Lewis DR, Chen HS, Feuer EJ and Cronin KA: SEER Cancer Statistics Review, 1975-2014, National Cancer Institute. Bethesda, MD, USA. https://seer.cancer.gov/csr/1975_2014/. Last accessed: 9th September 2017.

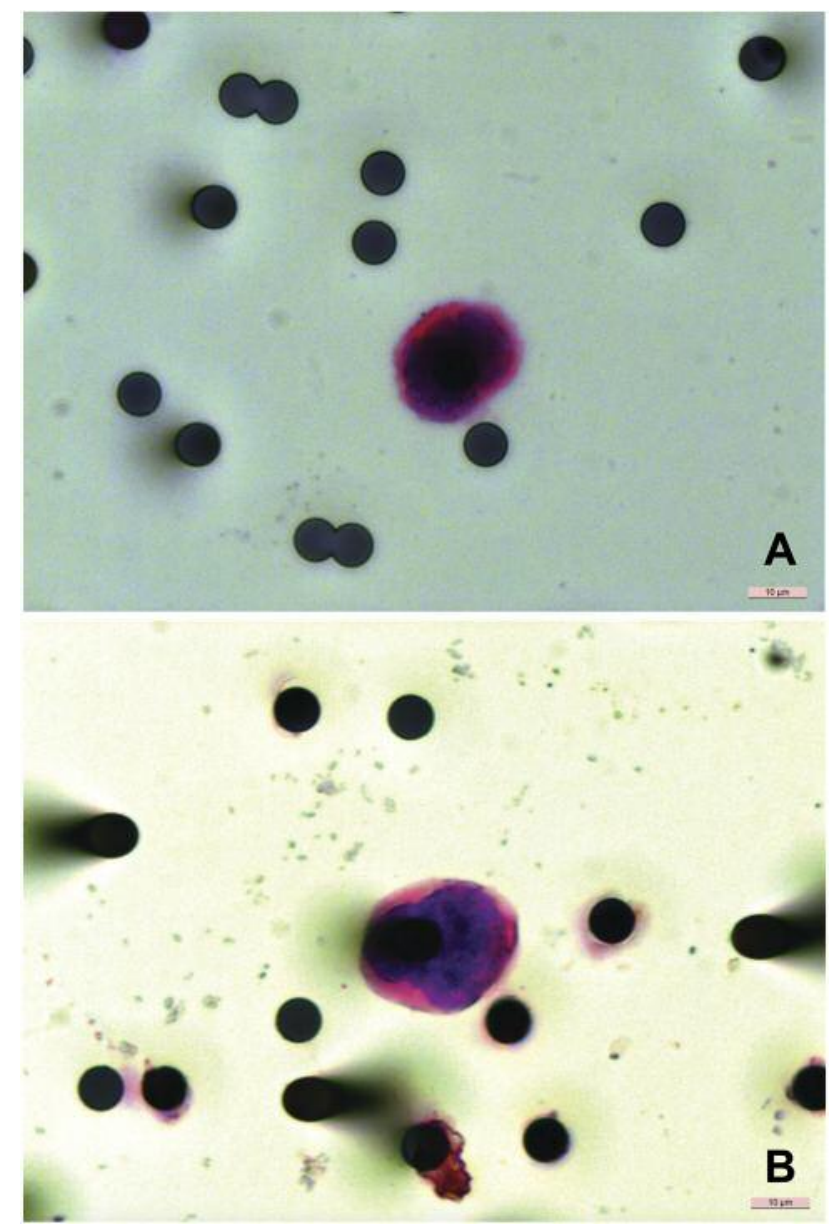

Figure 1. Images of pre-treatment (A) and post-treatment (B) blood samples of our patient with non small cell lung cancer used for circulating tumor cell (CTC) count. Total CTC count: was 4 pre treatment and 10 post-treatment.

2 Molina JR, Yang P, Cassivi SD, Schild SE and Adjei AA: NonSmall Cell Lung Cancer: Epidemiology, Risk Factors, Treatment, and Survivorship. Mayo Clin Proc 83: 584-594, 2008.

3 Bednarz-Knoll N, Alix-Panabières $\mathrm{C}$ and Pantel K: Clinical relevance and biology of circulating tumor cells. Breast Cancer Res 13: 228, 2011.

4 Cohen SJ, Punt CJ, Iannotti N, Saidman BH, Sabbath KD, Gabrail NY, Picus J, Morse M, Mitchell E, Miller MC, Doyle GV, Tissing H, Terstappen LW and Meropol NJ: Relationship of circulating tumor cells to tumor response, progression-free survival, and overall survival in patients with metastatic colorectal cancer. J Clin Oncol 26(19): 3213-3221, 2008.

5 de Bono JS, Scher HI, Montgomery RB, Parker C, Miller MC, Tissing H, Doyle GV, Terstappen LW, Pienta KJ and Raghavan D: Circulating tumor cells predict survival benefit from treatment in metastatic castration-resistant prostate cancer. Clin Cancer Res 14(19): 6302-6309, 2008. 

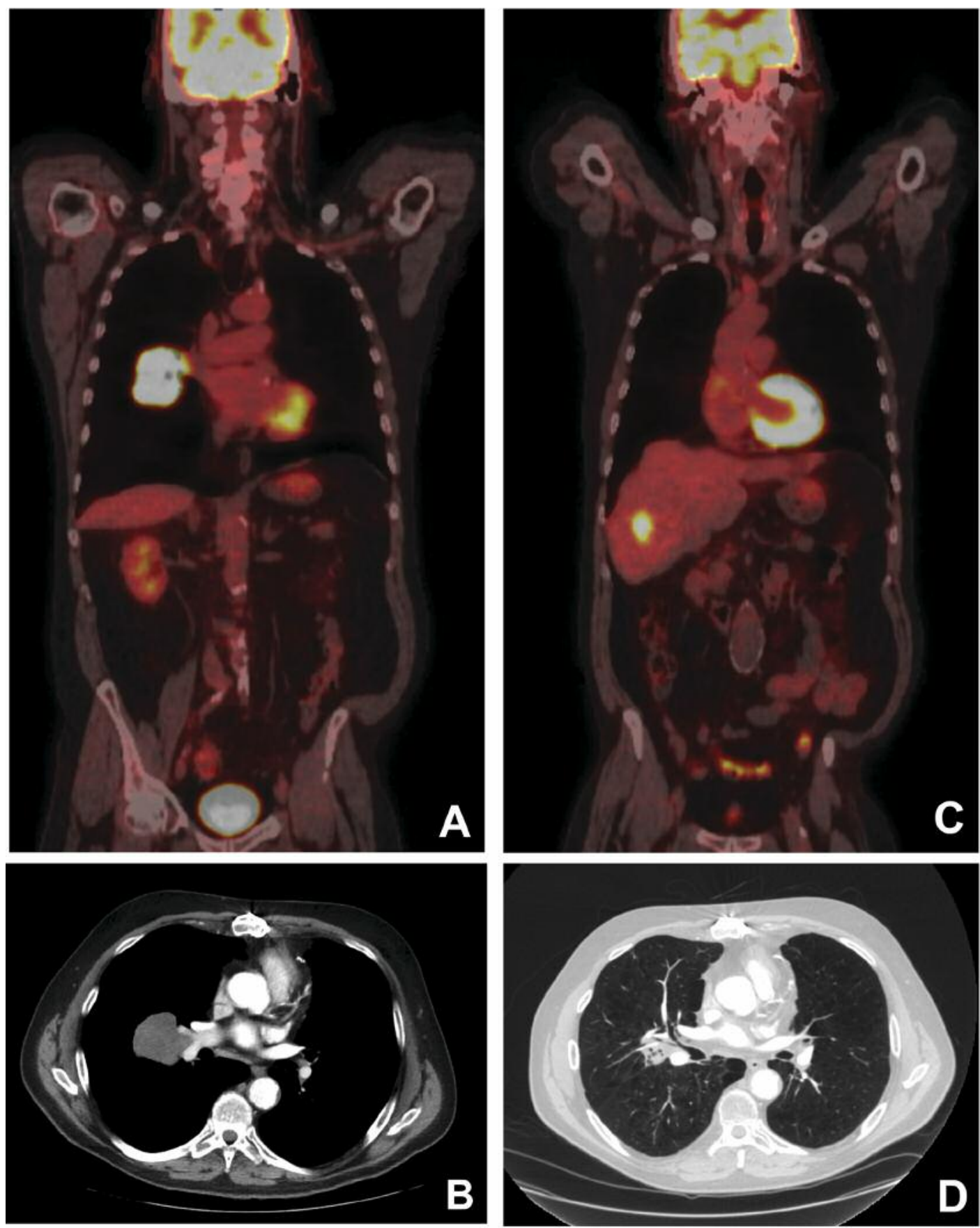

Figure 2. A, B: Pre-treatment positron-emission tomography (PET) and computerized tomography (CT) scans demonstrating primary lung tumor and normal liver. C, D: Post-treatment PET and CT demonstrating liver metastasis and shrinkage of primary tumor.

6 Cristofanilli M, Budd GT, Ellis MJ, Stopeck A, Matera J, Miller MC, Reuben JM, Doyle GV, Allard WJ, Terstappen LW and Hayes DF: Circulating tumor cells, disease progression, and survival in metastatic breast cancer. N Engl J Med 351(8): 781791,2004
7 Hou JM, Krebs MG, Lancashire L, Sloane R, Backen A, Swain RK, Priest LJ, Greystoke A, Zhou C, Morris K, Ward T, Blackhall FH and Dive C: Clinical significance and molecular characteristics of circulating tumor cells and circulating tumor microemboli in patients with small-cell lung cancer. J Clin Oncol 30(5): 525-532, 2012. 
8 Budd GT, Cristofanilli M, Ellis MJ, Stopeck A, Borden E, Miller MC, Matera J, Repollet M, Doyle GV, Terstappen LW and Hayes DF: Circulating tumor cells versus imaging - predicting overall survival in metastatic breast cancer. Clin Cancer Res 12(21): 6403-6409, 2006.

9 Wu C, Hao H, Li L, Zhou X, Guo Z, Zhang L, Zhang X, Zhong W, Guo H, Bremner RM and Lin P: Preliminary investigation of the clinical significance of detecting circulating tumor cells enriched from lung cancer patients. J Thorac Oncol 4(1): 30-36, 2009.

Received November 21, 2017

Revised December 9, 2017

Accepted December 13, 2017 